\title{
Mycobacterium seoulense sp. nov., a slowly growing scotochromogenic species
}

\author{
Ho-Suk Mun, ${ }^{1}$ Hyun-Ju Kim, ${ }^{1}$ Eun-Ju Oh, ${ }^{1}$ Hong Kim, ${ }^{1}$ Gil-Han Bai, ${ }^{2}$ \\ Hee-Kyung $\mathrm{Yu}^{2}{ }^{2}$ Young-Gil Park, ${ }^{2}$ Chang-Yong Cha, ${ }^{1}$ Yoon-Hoh Kook ${ }^{1}$ \\ and Bum-Joon Kim ${ }^{1}$
}

Correspondence

Bum-Joon Kim

kbumjoon@snu.ac.kr

\author{
${ }^{1}$ Department of Microbiology and Immunology, Cancer Research Institute and Liver Research \\ Institute, College of Medicine, Seoul National University, Seoul 110-799, Korea \\ ${ }^{2}$ The Korean Institute of Tuberculosis, The Korean National Tuberculosis Association, Seoul \\ 137-140, Korea
}

\begin{abstract}
A previously undescribed, slowly growing, scotochromogenic mycobacterium was isolated from a patient with symptomatic pulmonary infection during $h s p 65$ sequence-based identification of Korean clinical isolates. Phenetic characteristics of this strain were generally similar to those of Mycobacterium nebraskense and Mycobacterium scrofulaceum. However, some phenetic characteristics differentiated it from these two species. Its 16S rRNA gene sequences were unique and phylogenetic analysis based on 16S rRNA gene sequences placed the organism in the slowly growing Mycobacterium group close to $M$. nebraskense and $M$. scrofulaceum. Its unique mycolic acid profiles and the results of phylogenetic analysis based on two independent alternative chronometer molecules, hsp65 and rpoB, confirmed the taxonomic status of this strain as representing a novel species. These data support the conclusion that this strain represents a novel mycobacterial species, for which the name Mycobacterium seoulense sp. nov. is proposed. The type strain is strain $03-19^{\top}\left(=\mathrm{DSM} 44998^{\top}=\mathrm{KCTC}^{19146^{\top}}\right)$.
\end{abstract}

Mycobacteria are widely distributed in the environment; some are pathogenic to humans and animals and, of these, a number are saprophytes. Recently, the application of molecular techniques to the taxonomy and identification of isolates from environmental sources and clinical specimens has led to an increased awareness of the diversity within the genus Mycobacterium (Kirschner et al., 1993). Conventional biochemical tests have been performed extensively to detect and identify Mycobacterium tuberculosis and clinically important non-tuberculous mycobacteria (Goodfellow \& Magee, 1998; Wayne \& Kubica, 1986). However, because of the increasing number of newly defined taxa and the recognition of 'difficult-to-identify' variants of known species, tests sometimes fail to provide precise identification (Kirschner et al., 1993). To overcome the limitations of conventional methods, sequencing methods targeting several chronometer molecules have been developed (Kim et al., 1999, 2005; Roth et al., 1998; Stahl \& Urbance, 1990;

Abbreviations: EMB, ethambutol; PNB, p-nitrobenzoate; SGM, slowly growing mycobacteria; $\mathrm{TCH}$, thiophene-2-carboxylic acid hydrazide.

The GenBank/EMBL/DDBJ accession numbers for the partial $16 \mathrm{~S}$ rRNA gene, $h s p 65$ and $r p o B$ sequences of strain $03-19^{\top}$ are respectively D0536403, D0536401 and D0536405.

Sequence alignments and neighbour-joining trees based on hsp65 and $r p o B$ sequences are available as supplementary material in IJSEM Online.
Stone et al., 1995). Moreover, the combination of molecular assays and conventional methods provides conclusive identification of infrequently encountered species and allows the delimitation of novel taxa. In the present study, a novel nontuberculous mycobacterial species was isolated from a patient with general symptoms of pulmonary infection. The organism was discovered during an exercise designed to identify Korean slowly growing mycobacteria (SGM) clinical isolates using the recently developed $h s p 65$ sequencing method (Kim et al., 2005).

The subject strain of the present study, strain $03-19^{\mathrm{T}}$, was one of the 'difficult-to-identify' isolates submitted to the Korean Institute of Tuberculosis by mycobacteriology laboratories in Korea during 2003. This strain was isolated from sputum samples of a 52 -year-old female who had been experiencing general pulmonary symptoms. The same strain was isolated from sputum specimens obtained from this patient on three successive occasions; no other mycobacterium was observed.

The phenetic characteristics of strain $03-19^{\mathrm{T}}$ and eight mycobacteria reference strains were analysed and compared (Table 1). Colony morphology, pigment production in the dark, photoinduction and the ability to grow at temperatures ranging from 25 to $45^{\circ} \mathrm{C}$ were examined during a 6 week incubation on Lowenstein-Jensen (LJ) medium and Middlebrook 7H10 agar. Acid-alcohol-fastness was 
Table 1. Cultural and biochemical characteristics that differentiate $03-19^{\top}$ from other closely related SGM species

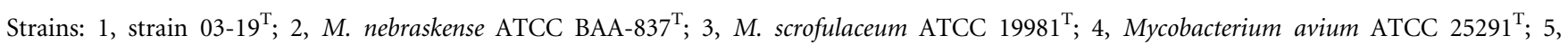
Mycobacterium terrae ATCC $15755^{\mathrm{T}}$; 6, M. kansasii ATCC $12478^{\mathrm{T}} ; 7$, Mycobacterium phlei ATCC $11758^{\mathrm{T}}$; 8 , Mycobacterium gordonae ATCC $14470^{\mathrm{T}}$; 9, Mycobacterium triviale ATCC $23292^{\mathrm{T}} .+++$, Highest level of growth; ++ , higher level of growth; + , positive result or modest growth; -, negative result or no growth; \pm , variable. All strains showed negative results in niacin and EMB tests and positive results in catalase and pyrazinamidase tests.

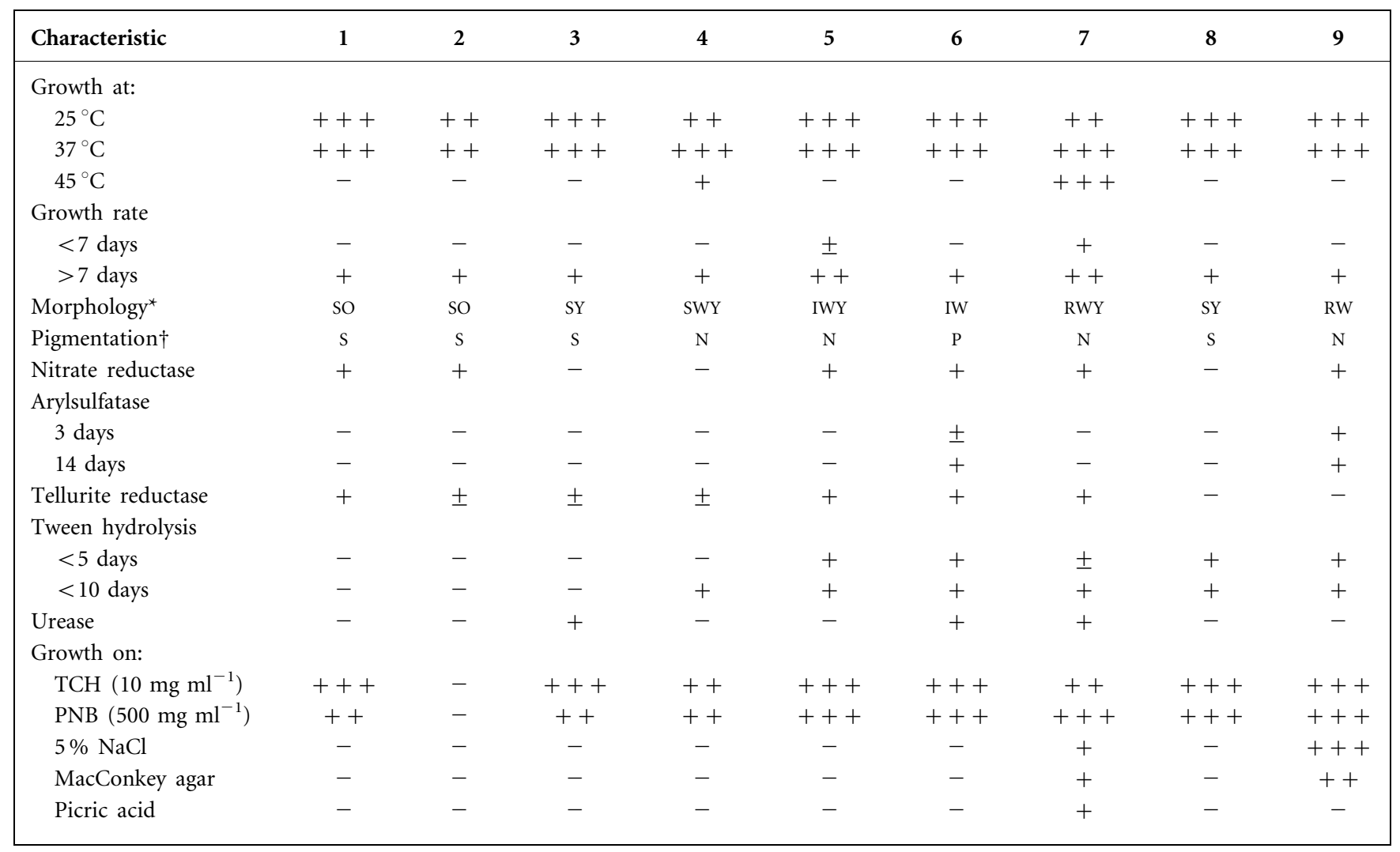

${ }^{\star} \mathrm{I}$, Intermediate in roughness; $\mathrm{R}$, rough; S, smooth; O, orange; $\mathrm{W}$, white; Y, yellow.

$\dagger \mathrm{N}$, Non-photochromogenic; P, photochromogenic; s, scotochromogenic.

determined by Ziehl-Neelsen and auramine $\mathrm{O}$ staining. The following biochemical features (Kent \& Kubica, 1985) were investigated: niacin accumulation, nitrate reductase, arylsulfatase on days 3 and 14, heat-stable catalase $(\mathrm{pH} 7$, $68^{\circ} \mathrm{C}$ ), tellurite reductase, Tween 80 hydrolysis, urease and pyrazinamidase. Inhibition tests included tolerance of thiophene-2-carboxylic acid hydrazide (TCH), p-nitrobenzoate (PNB), $5 \%$ sodium chloride, ethambutol (EMB) and picric acid and ability to grow on MacConkey agar without crystal violet.

HPLC was used to analyse mycolic acids from strain $03-19^{\mathrm{T}}$ and the most phenotypically similar strain, Mycobacterium nebraskense ATCC BAA- $837^{\mathrm{T}}$, as described by Butler et al. (1992) or as described in the guidelines of the CDC National Center for HIV, STD, and TB Prevention Division of Tuberculosis Elimination (http://www.cdc.gov/nchstp/tb/ Laboratory_Services/Liquid_Chroma.htm). Low- and highmolecular-mass standards (Ribi ImmunoChem) were added for peak identification. To identify and quantify mycolic acids and assign these to Mycobacterium species based on mycolic acid patterns, the Microbial Identification system (MIDI Inc.) was used.

Chromosomal DNA for molecular taxonomy was extracted using the bead-beater phenol extraction method as reported previously (Kim et al., 2005). Purified DNA was used as a template for PCR amplifications of three independent genes, the 16S rRNA gene, hsp65 (encoding heat-shock protein 65) and $r p o B$ (encoding a subunit of RNA polymerase). The nearly complete $16 \mathrm{~S}$ rRNA gene sequence (1523 bp) and partial sequences of $h s p 65$ (644 bp) and $r p o B$ (352 bp) were amplified as described previously (Springer et al., 1996; Kim et al., 1999, 2005). PCR amplicons of all target genes were cloned directly using Topo TA cloning kits (Invitrogen) and sequenced (Kim et al., 2005). To obtain sequence information on the $r p o B$ and hsp65 genes of M. nebraskense, which were not available in GenBank, these sequences were also analysed from $M$. nebraskense ATCC BAA- $837^{\mathrm{T}}$, purchased from the ATCC. The 16S rRNA gene sequence of $03-19^{\mathrm{T}}$ 
obtained in the present study was compared with sequences from GenBank using the BLAST analysis program (http:// www.ncbi.nlm.nih.gov/blast/).

Multiple alignments of sequences of the three genes of 03$19^{\mathrm{T}}$ and reference strains of a wide range of both slowly and rapidly growing mycobacteria were created using the multiple-alignment algorithm in MEGALIGN as described previously (Kim et al., 1999, 2005). All three trees were inferred by neighbour joining (Saitou \& Nei, 1987) and maximum parsimony (Fitch, 1971) using Tsukamurella paurometabola strain NCTC 10741 (16S rRNA gene) or strain KCTC $9821^{\mathrm{T}}$ (hsp65) or Rhodococcus equi ATCC $10146^{\mathrm{T}}(r p o B)$ as an outgroup. Evolutionary distance matrices were generated according to the model described by Jukes \& Cantor (1969). The neighbour-joining and maximum-parsimony methods were carried out using MEGA version 2.1 (Kumar et al., 2001) and the resulting trees and topologies were evaluated by bootstrap analyses (Felsenstein, 1985) based on 1000 resamplings.

Acid-fast microscopy showed generally rod-shaped and frequently bent acid-fast bacilli. Occasional coccid forms were noted. Spores and filaments were not present. The optimal growth temperature was $37^{\circ} \mathrm{C}$. No growth was observed at $45^{\circ} \mathrm{C}$. On Middlebrook 7H10 medium, mature growth developed in 3 weeks at 25 and $37^{\circ} \mathrm{C}$. Microcolonies developed in 2 weeks at the same temperature. However, 4 weeks or more was required for mature colonies to form on LJ medium. Colonies grown on Middlebrook 7H10 agar were usually larger, smooth, occasionally rough, and always orange in appearance under both dark and photoinduction conditions. Cells on LJ medium were film-like and produced an orange pigment. No growth was observed on MacConkey agar, after the addition of $5 \% \mathrm{NaCl}$ to the culture medium or after adding $5 \mathrm{mg}$ EMB ml $\mathrm{ml}^{-1}$ or picric acid to the medium. However, strain $03-19^{\mathrm{T}}$ showed tolerance against $10 \mathrm{mg} \mathrm{TCH} \mathrm{ml}{ }^{-1}$ and against $500 \mathrm{mg} \mathrm{PNB} \mathrm{ml} \mathrm{m}^{-1}$. The strain was negative for urease activity, arylsulfatase, niacin accumulation and Tween 80 hydrolysis and positive for nitrate reductase, heat-stable catalase, pyrazinamidase and tellurite reductase. Generally, the biochemical profile of $03-19^{\mathrm{T}}$ was most like those of M. nebraskense, another scotochromogenic species. However, since a difference was found between these two species in terms of tolerance against $\mathrm{TCH}$ and $\mathrm{PNB}$, such tests might be used to differentiate the two taxa. Cultural and biochemical characteristics that differentiate $03-19^{\mathrm{T}}$ from other closely related SGM species are shown in Table 1.

In HPLC analysis of mycolic acids, the profile of strain 03$19^{\mathrm{T}}$ showed two clusters of peaks that did not overlap with any previously reported mycobacterial profile. The closest match was with the Mycobacterium avium/intracellulare/ scrofulaceum complex, with a similarity index of 0.052 . In a comparison with the mycolic acids of M. nebraskense ATCC BAA $-837^{\mathrm{T}}$ (Fig. 1), differences were found in the relative heights of peaks as follows: peak $1,2.70 \%$ (strain $03-19^{\mathrm{T}}$ ) and $10.45 \%\left(\right.$ M. nebraskense ATCC BAA- $\left.837^{\mathrm{T}}\right)$; peak 2, 1.53
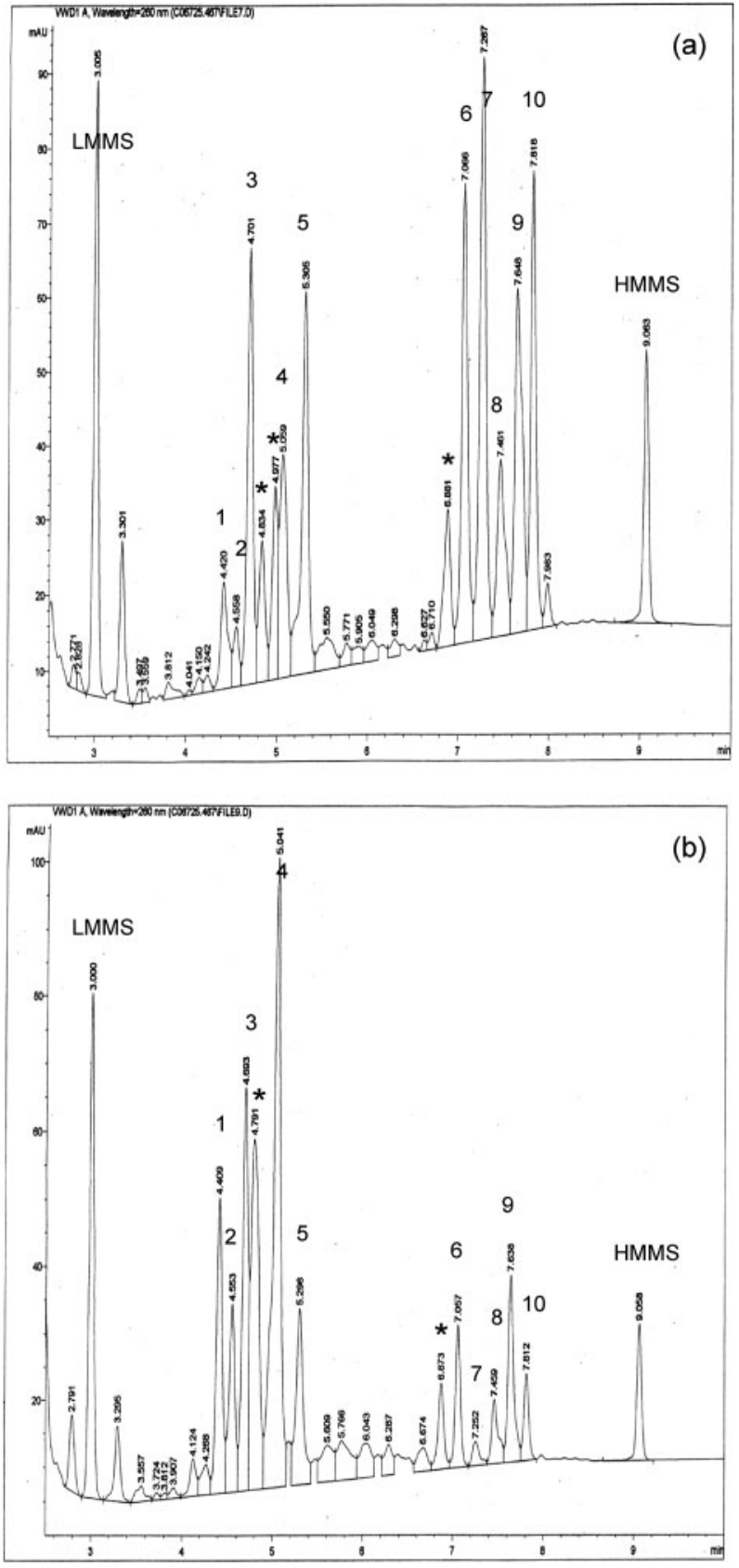

Fig. 1. Mycolic acid patterns of strain $03-19^{\top}$ (a) and $M$. nebraskense ATCC BAA- $837^{\top}$ (b) obtained by HPLC analysis. The relative retention time is indicated for each peak. LMMS, Low-molecular-mass standard; HMMS, high-molecular-mass standard. Asterisks $\left(^{*}\right)$ indicate peaks specific to either $03-19^{\top}$ or $M$. nebraskense ATCC BAA- $837^{\top}$.

and $6.64 \%$; peak 3, 11.16 and $14.21 \%$; peak 4, 5.67 and $22.20 \%$; peak 5, 9.74 and $6.23 \%$; peak 6, 11.74 and $5.06 \%$, peak 7, 14.88 and $0.84 \%$; peak $8,4.48$ and $2.27 \%$; peak 9 , 8.79 and $6.64 \%$, and peak $10,11.76$ and $3.08 \%$. Such differences in HPLC peak heights have been reported to be species-specific for mycobacteria (CDC, 1996, 1999; Duffey 
et al., 1996; Floyd et al., 1996). Furthermore, three unique peaks (retention times 4.834, 4.977 and $6.881 \mathrm{~min}$ ) distinguished strain $03-19^{\mathrm{T}}$ from $M$. nebraskense ATCC BAA- $837^{\mathrm{T}}$.

A BLAST search of the GenBank database using 16S rRNA gene sequences of strain $03-19^{\mathrm{T}}$ gave a closest match $(99 \%)$ to Mycobacterium sp. IWGMT 90160 and the second best match to M. nebraskense UNMC-MY $1349^{\mathrm{T}}$ ( = ATCC BAA$\left.837^{\mathrm{T}}\right)(99 \%)$. The $16 \mathrm{~S}$ rRNA gene of $03-19^{\mathrm{T}}$ differed from that of Mycobacterium sp. IWGMT 90160 by one deletion and eight substitutions and from that of $M$. nebraskense UNMC-MY $1349^{\mathrm{T}}$ by one deletion and 11 substitutions. In hypervariable region ' $A$ ' of the $16 \mathrm{~S}$ rRNA gene, five and four differences were observed, respectively, between $03-19^{\mathrm{T}}$ and M. nebraskense UNMC-MY $1349^{\mathrm{T}}$ and Mycobacterium sp. IWGMT 90160. In hypervariable region 'B', a unique 1 bp deletion distinguished strain $03-19^{\mathrm{T}}$ from these closely related strains (Fig. 2). Perhaps these polymorphisms in the $16 \mathrm{~S}$ rRNA gene could be used to detect this strain in the future.

A neighbour-joining tree based on the aligned 16S rRNA gene sequences of strain $03-19^{\mathrm{T}}$ and 42 other Mycobacterium strains indicated a close relationship between strain $03-19^{\mathrm{T}}$ and M. nebraskense, Mycobacterium scrofulaceum and Mycobacterium sp. IWGMT 90160 within the SGM. The high bootstrapping values and topology of the maximumparsimony tree strongly supported the grouping of these species (Fig. 3).

Trees based on $h s p 65$ and $r p o B$ gene sequences showed different groupings of strain $03-19^{\mathrm{T}}$, compared with the $16 \mathrm{~S}$ rRNA gene sequences. In the $h s p 65$ neighbour-joining tree (Supplementary Fig. S1 available in IJSEM Online), strain $03-19^{\mathrm{T}}$ was closely related to Mycobacterium interjectum, rather than to M. nebraskense or M. scrofulaceum, and this was strongly supported by high bootstrap values and the recovery of this grouping in the maximum-parsimony tree. In the $r p o B$ neighbour-joining tree (Supplementary Fig. S2), strain $03-19^{\mathrm{T}}$ was closely related to Mycobacterium xenopi. In spite of low bootstrap values, the same grouping was observed in the maximum-parsimony tree. Overall, phylogenetic analysis based on the three different gene sequences showed slightly different results for the relationship of strain $03-19^{\mathrm{T}}$ to known species. The distinct grouping of $03-19^{\mathrm{T}}$ among different trees confirmed the taxonomic status of this strain as a member of a novel species. It also strongly supported the notion that the description of the novel species could not have been achieved with results from a single gene. Sequence alignments of partial $h s p 65$ and $r p o B$ genes for strain $03-19^{\mathrm{T}}$ and closely related strains are available as Supplementary Fig. S3(a, b) in IJSEM Online.

The distinct sequences of these three gene targets together with the uniqueness of its mycolic acid profile and phenetic traits confirm the taxonomic status of strain $03-19^{\mathrm{T}}$ as a member of a novel mycobacterial species rather than a variant of a previously described species. Moreover, the successive isolations of this strain from sputum samples of a patient at different stages in the absence of other mycobacteria strongly support the possibility that it may be a causative agent of pulmonary disease.

\section{Description of Mycobacterium seoulense sp. nov.}

Mycobacterium seoulense (seo.ul.en'se. N.L. neut. adj. seoulense pertaining to Seoul, Republic of Korea, the geographical origin of the type strain).

The bacillus stains acid-alcohol-fast. Cells are generally rodshaped and frequently bent. Occasional coccid forms are noted. Spores and filaments are not present. The optimal

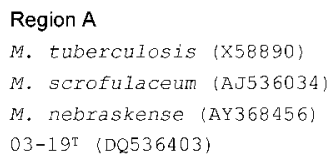

80

$80 \quad 125$

... C.C ......G.G ....

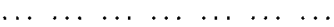

... C.C..... G.G ... . .
TGG GTG ATC TGC CCT GCA CTT CGG GAT RAG CCT GGG AAA CTG GGT CTA ATA CCG GAT

$\begin{array}{llllllllllllllllllllllll}\ldots & \ldots & \ldots & \ldots & \ldots & \ldots & \ldots & \ldots & \ldots & \ldots & \ldots & \ldots & \ldots & \ldots & \ldots & \ldots & \ldots & \ldots & \ldots\end{array}$

$\begin{array}{lllllllllllllllllll}\ldots & \ldots & \ldots & \ldots & \ldots & \ldots & \ldots & \ldots & \ldots & \ldots & \ldots & \ldots & \ldots & \ldots & \ldots & \ldots & \ldots & \ldots & A\end{array}$

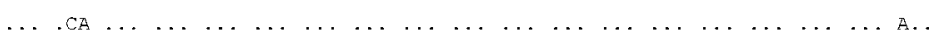

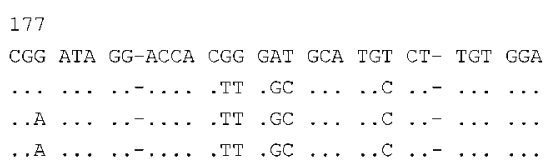

445

TCG ACG AAG G-- TCC GGG TTC TCT CGG ATT GAC GGT AGg TGG AGA AGA AGC ACC GGC CAA CTA CGT GCC AGC

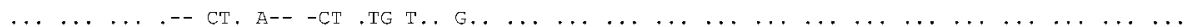

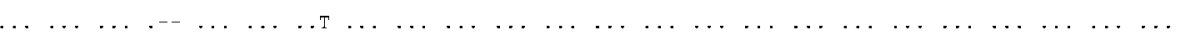

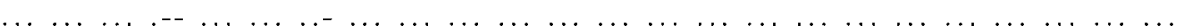

M. tuberculosis (X58890)

M. scrofulaceum (AJ536034)

M. nebraskense (AY368456)

03-19т (DQ536403)

Fig. 2. Alignment of hypervariable regions $A$ and $B$ of the $16 S$ rRNA gene from strain $03-19^{\top}$ and genotypically similar reference strains. Nucleotide positions are indicated according to the Escherichia coli sequence. Species are represented by the corresponding type strains. The sequence of $03-19^{\top}$ was determined in the present study; other sequences were obtained from GenBank. 


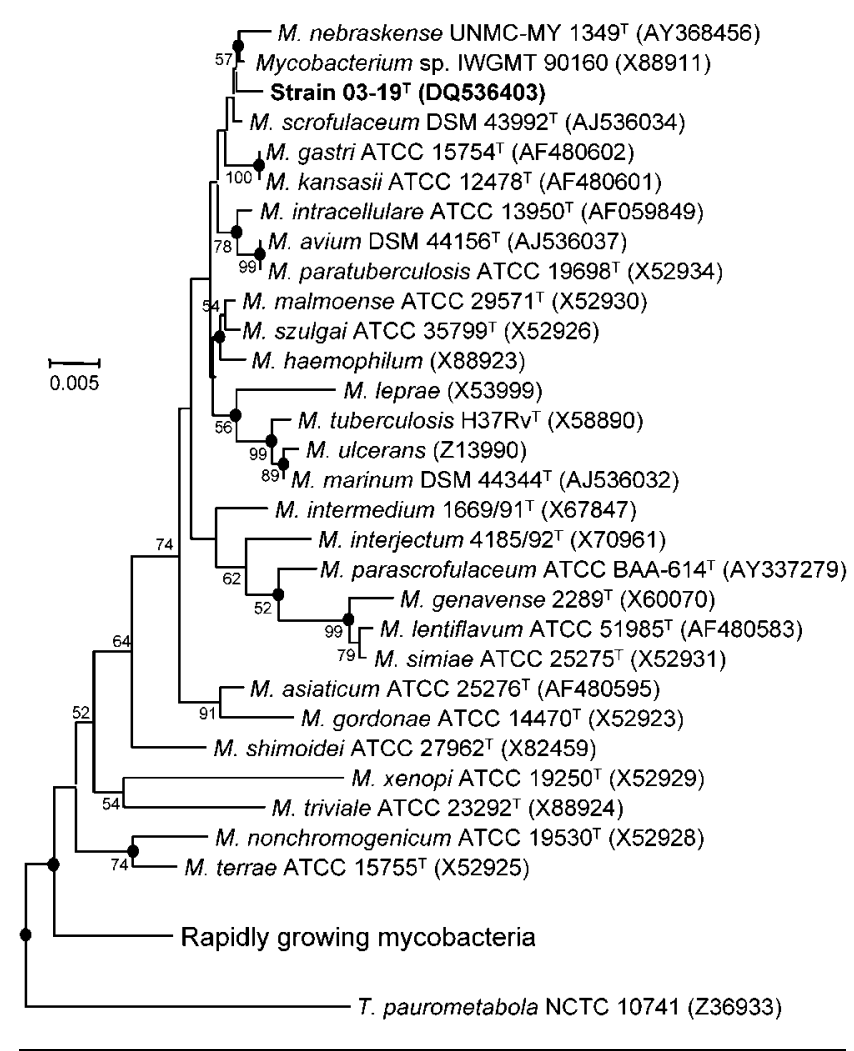

Fig. 3. Phylogenetic relationships of strain $03-19^{\top}$ among other Mycobacterium species based on 16S rRNA gene sequences. The tree was constructed using the neighbour-joining method. Percentages indicated at nodes represent bootstrap levels supported by 1000 resampled datasets. Bootstrap values of $<50 \%$ are not shown. Shaded circles indicate that the corresponding nodes (groupings) were also recovered in the maximum-parsimony tree (not shown). T. paurometabola NCTC 10741 was used as an outgroup in both trees. Bar, $0.5 \%$ sequence difference.

growth temperature is $37^{\circ} \mathrm{C}$. No growth is observed at $45^{\circ} \mathrm{C}$. On Middlebrook 7H10 medium, mature growth develops in 3 weeks at 25 and $37^{\circ} \mathrm{C}$. Microcolonies develop in 2 weeks at the same temperature. However, 4 weeks or more is required for mature colonies to form on LJ medium. Colonies grown on Middlebrook 7H10 agar are usually larger and smooth, although occasionally rough, but always orange in appearance, under both dark and photoinduction conditions. Cells on LJ medium grow in a film-like manner and produce an orange pigment. No growth is observed on MacConkey agar or on culture medium containing $5 \%$ $\mathrm{NaCl}$ or $5 \mathrm{mg} \mathrm{EMB} \mathrm{ml}^{-1}$. Negative for urease activity, arylsulfatase and Tween 80 hydrolysis and positive for nitrate reductase, heat-stable catalase, pyrazinamidase and tellurite reductase. HPLC analysis shows a unique mycolic acid profile. Genetically, the organism has sequences unique amongst species of Mycobacterium for the 16S rRNA, hsp65 and $r p o B$ genes. Phylogenetic analysis using $16 \mathrm{~S}$ rRNA gene sequences shows that M. seoulense belongs to the SGM and is closely related to $M$. nebraskense, M. scrofulaceum and Mycobacterium kansasii.

The type strain is $03-19^{\mathrm{T}}\left(=\mathrm{DSM} 44998^{\mathrm{T}}=\mathrm{KCTC} 19146^{\mathrm{T}}\right)$, isolated from human sputum samples in Seoul, Republic of Korea.

\section{Acknowledgements}

This study was supported by grant no. 03-2005-027-0 from the SNUH Research fund and in part by the BK21 Project for Medicine.

\section{References}

Butler, W. R., Thibert, L. \& Kilburn, J. O. (1992). Identification of Mycobacterium avium complex strains and some similar species by high-performance liquid chromatography. J Clin Microbiol 30, 2698-2704.

CDC (1996). Standardized method for HPLC identification of mycobacteria. Atlanta, GA: Centers for Disease Control and Prevention. http://www.cdc.gov/ncidod/publications/hplc.pdf

CDC (1999). Mycolic acid pattern standards for HPLC identification of mycobacteria. Atlanta, GA: Centers for Disease Control and Prevention. http://www.cdc.gov/nchstp/tb/Laboratory_Services/maps _tagged.pdf

Duffey, P. S., Guthertz, L. S. \& Evans, G. C. (1996). Improved rapid identification of mycobacteria by combining solid-phase extraction with high-performance liquid chromatography analysis of BACTEC cultures. J Clin Microbiol 34, 1939-1943.

Felsenstein, J. (1985). Confidence limits on phylogenies: an approach using the bootstrap. Evolution 39, 783-791.

Fitch, W. M. (1971). Toward defining the course of evolution: minimum change for a specific tree topology. Syst Zool 20, 406-416.

Floyd, M. M., Guthertz, L. S., Silcox, V. A., Duffey, P. S., Jang, Y., Desmond, E. P., Crawford, J. T. \& Butler, W. R. (1996). Characterization of an SAV organism and proposal of Mycobacterium triplex sp. nov. J Clin Microbiol 34, 2963-2967.

Goodfellow, M. \& Magee, J. G. (1998). Taxonomy of mycobacteria. In Mycobacteria, vol. 1, Basic Aspects, pp. 1-71. Edited by P. R. J. Gangadharam \& P. A. Jenkins. New York \& London: Chapman \& Hall.

Jukes, T. H. \& Cantor, C. R. (1969). Evolution of protein molecules. In Mammalian Protein Metabolism, pp. 21-132. Edited by H. N. Munro. New York: Academic Press.

Kent, P. T. \& Kubica, G. P. (1985). Public Health Mycobacteriology. Guide for the level III Laboratory. US Department of Health and Human Service publication. Atlanta, GA: Centers for Disease Control and Prevention.

Kim, B. J., Lee, S. H., Lyu, M. A., Kim, S. J., Bai, G. H., Chae, G. T., Kim, E. C., Cha, C. Y. \& Kook, Y. H. (1999). Identification of mycobacterial species by comparative sequence analysis of the RNA polymerase gene (rpoB). J Clin Microbiol 37, 1714-1720.

Kim, H., Kim, S.-H., Shim, T.-S., Kim, M.-n., Bai, G.-H., Park, Y.-G., Lee, S.-H., Chae, G.-T., Cha, C.-Y. \& other authors (2005). Differentiation of Mycobacterium species by analysis of the heatshock protein 65 gene (hsp65). Int J Syst Evol Microbiol 55, 1649-1656.

Kirschner, P., Springer, B., Vogel, U., Meier, A., Wrede, A., Kiekenbeck, M., Bange, F. C. \& Bottger, E. C. (1993). Genotypic identification of mycobacteria by nucleic acid sequence determination: 
report of a 2-year experience in a clinical laboratory. J Clin Microbiol 31, 2882-2889.

Kumar, S., Tamura, K., Jakobsen, I.-B. \& Nei, M. (2001). MEGA2: molecular evolutionary genetics analysis software. Tempe, AZ: Arizona State University.

Roth, A., Fischer, M., Hamid, M. E., Michalke, S., Ludwig, W. \& Mauch, H. (1998). Differentiation of phylogenetically related slowly growing mycobacteria based on 16S-23S rRNA gene internal transcribed spacer sequences. J Clin Microbiol 36, 139-147.

Saitou, N. \& Nei, M. (1987). The neighbor-joining method: a new method for reconstructing phylogenetic trees. Mol Biol Evol 4, 406-425.

Springer, B., Stockman, L., Teschner, K., Roberts, G. D. \& Bottger,

E. C. (1996). Two-laboratory collaborative study on identification of mycobacteria: molecular versus phenotypic methods. J Clin Microbiol 34, 296-303.

Stahl, D. A. \& Urbance, J. W. (1990). The division between fast- and slow-growing species corresponds to natural relationships among the mycobacteria. J Bacteriol 172, 116-124.

Stone, B. B., Nietupski, R. M., Breton, G. L. \& Weisburg, W. G. (1995). Comparison of Mycobacterium 23S rRNA sequences by hightemperature reverse transcription and PCR. Int J Syst Bacteriol 45, 811-819.

Wayne, L. G. \& Kubica, G. P. (1986). The mycobacteria. In Bergey's Manual of Determinative Bacteriology, 9th edn, pp. 1435-1457. Edited by R. E. Buchanan \& N. E. Gibbons. Baltimore: Williams \& Wilkins. 